\title{
Hubungan Penerapan Perilaku Kadarzi (Keluarga Sadar Gizi) dengan Status Gizi Balita di Kabupaten Tulungagung
}

\section{Relationship of Kadarzi (Family Conscious Nutrition) Behavior Practice to Nutritional Status of Children Under Five Years in Tulungagung District}

\author{
Santik Wijayanti* ${ }^{1}$, Triska Susila Nindya ${ }^{1}$
}

\begin{abstract}
ABSTRAK
Latar belakang: Keluarga Sadar Gizi (Kadarzi) merupakan program pemerintah Indonesia yang bertujuan mengatasi masalah gizi. Keluarga diharapkan dapat secara mandiri mewujudkan keadaan gizi yang sebaik-baiknya untuk meningkatkan kesehatan. Setiap indikator Kadarzi memiliki peran penting untuk mengatasi dan mencegah terjadinya masalah gizi seperti indikator pemberian suplemen vitamin A digunakan untuk mengatasi kekurangan vitamin A. Masalah gizi dapat dilihat salah satunya dengan menggunakan status gizi. Balita merupakan usia yang rawan mengalami masalah gizi seperti underweight, stunting, dan wasting.

Tujuan: Tujuan dari penelitian ini adalah menganalisis hubungan antara penerapan perilaku Kadarzi dengan status gizi balita (BB/U, TB/U, dan BB/TB).

Metode: Penelitian ini merupakan penelitian observasinol analitik, dengan desain penelitian cross sectional. Sampel terdiri dari 72 balita di Desa Salakkembang, Kecamatan Kalidawir, Kabupaten Tulungagung. Pengumpulan data menggunakan penimbangan berat badan, tinggi badan, dan kuesioner perilaku Kadarzi. Data dianalisis menggunakan Fisher Exact test.

Hasil: Hasil dari penelitian menunjukkan terhadap hubungan antara perilaku Kadarzi dengan status gizi balita $B B / U(p=0,010)$ dan TB/U $(p=0,000)$ namun tidak dengan $B B / T B(p=0,368)$.

Kesimpulan: Semakin baik penerapan perilaku Kadarzi maka semakin baik status gizi balita BB/U dan TB/U. Ibu dan seluruh anggota keluarga seharusnya menerapkan perilaku Kadarzi agar balita terhindar dari masalah gizi.
\end{abstract}

Kata kunci: balita, kadarzi, status gizi 


\section{ABSTRACT}

Background: Family conscious nutrition (Kadarzi) is an Indonesia government program that aims to address the nutrition problem. The family expected to be able to independently giving the best nutrition to improve health. Each Kadarzi indicator has an important role to resolve and prevent the occurrence of utrition problem as indicator of vitamin A supplementation is used to resolve vitamin $A$ deficiency. Nutrition problems can be seen by using nutritional status. Children under five years are age-prone to experiencenutritional problem such as underweight, stunting, and wasting.

Objective: The purpose of this study was to analyze the relationship between the application of Kadarzi behavior with the nutritional status of children under five (WAZ, HAZ, and WHZ).

Method: The research was an analytic obsevation research, using cross sectional design. The sample consist of 72 toddlers in Salakkembang Village, Kalidawir Subdistrict, Tulungagung Regency. The data were collected by using weight and height measurement, also Kadarzi bahavior questionnaire. The data were analyzed using Fisher Exact test.

Result: The results of the study showed that there was a correlation between Kadarzi behavior with nutitional status of toddlers based on WAZ $(p=0.010)$, and HAZ $(p=0.000)$ but not with WHZ ( $p=0.368)$.

Conclusion: The better apllication of Kadarzi behavior, the better the nutritional status of toddlers WAZ and HAZ. Mothers should apply Kadarzi behavior to prevent toddlers from nutritional problems.

Keywords: toddlers, family conscious nutrition, nutritional status

\footnotetext{
*Koresponden:

santik.jaya@gmail.com

${ }^{1}$ Departemen Gizi Kesehatan, Fakultas

Kesehatan Masyarakat-Universitas Airlangga
}

\section{PENDAHULUAN}

Kadarzi adalah keluarga yang berperilaku gizi seimbang yang mampu mengenal, mencegah dan mengatasi masalah gizi pada setiap anggota keluarganya ${ }^{1}$. Keluarga dikatakan memiliki perilaku Kadarzi yang baik jika sudah menerapkan lima indikator Kadarzi yaitu, menimbang berat badan secara rutin, memberikan ASI eksklusif, makan beraneka ragam, menggunakan garam beryodium dan mengonsumsi suplementasi zat gizi ${ }^{1}$. Hasil survei Kadarzi tahun 2010 menunjukkan terdapat 2 indikator yang menyebabkan capaian Kadarzi rendah yaitu memberikan ASI eksklusif dan makan beraneka ragam $^{2}$. Tulungagung merupakan salah satu Kabupaten yang berada di Jawa Timur dengan persentase keluarga yang berperilaku Kadarzi yaitu sebanyak 55\% pada tahun $2015^{3}$. Indikator Kadarzi yang menyebabkan capaian Kadarzi rendah di Tulungagung yaitu belum tercapainya pemberian ASI eksklusif dan menimbang berat badan secara rutin sesuai target $^{3}$. Penelitian yang dilakukan di Kalimantan Barat menunjukkan bahwa keluarga yang tidak menerapkan perilaku Kadarzi dengan baik memiliki balita dengan status gizi rendah ${ }^{4}$.

Penimbangan balita merupakan salah satu indikator yang sangat penting dilakukan untu mendeteksi adanya kasus gizi buruk dan gizi kurang. Penimbangan balita biasanya dilakukan satu bulan sekali di Posyandu. Ibu balita yang memanfaatkan Posyandu memiliki balita dengan status gizi baik dibandingkan ibu balita yang tidak memanfaatkan Posyandu ${ }^{5}$. Ibu yang memiliki pengetahuan yang baik memilki motivasi yang tinggi untuk membawa anaknya ke Posyandu karena semakin cepat penanganan masalah gizi pada anak maka akan mengurangi risiko kematian ${ }^{6}$.

Memberikan ASI eksklusif merupakan indikator Kadarzi yang sering tidak mencapai 
target di beberapa wilayah. Pemberian ASI eksklusif sangat penting untuk balita, karena ASI memiliki zat gizi yang dibutuhkan dan sesuai untuk bayi sehingga bayi yang tidak mendapat ASI eksklusif lebih berisiko mengalami kematian dibandingkan bayi yang mendapat ASI eksklusif ${ }^{7}$. Penelitian Giri dkk ${ }^{8}$ menunjukkan bahwa $74,4 \%$ ibu yang memberikan ASI eksklusif memiliki status gizi baik serta, penelitian ini menunjukkan bahwa ada hubungan antara pemberian ASI eksklusif dengan status gizi balita.

Asupan zat gizi merupakan hal penting, bagi tubuh untuk melakukan fungsinya seperti menghasilkan energi, membangun dan memelihara jaringan. Pemberian makanan yang tepat untuk anak dapat menurunkan masalah gizi, dimana anak yang mengkonsumsi makanan beragam memilki tingkat kesehatan yang baik ${ }^{9}$. Makan beraneka ragam untuk memenuhi kebutuhan zat gizi karena tidak ada satupun jenis makanan yang memiliki kandungan zat gizi lengkap. Makan beraneka ragam akan meningkatkan tingkat asupan zat gizi dan dapat menurunkan stunting pada balita $^{10}$.

Penggunaan garam beryodium merupakan salah satu indikator Kadarzi untuk menanggulangi gangguan akibat kurang yodium (GAKY). Keluarga yang tidak menggunakan garam beryodium memiliki kejadian stunting lebih besar dibandingkan keluarga yang menggunakan garam beryodium setiap harinya ${ }^{11}$. Selain menggunakan garam beryodium Suplementasi zat gizi vitamin A juga merupakan indikator Kadarzi untuk mengatasi masalah gizi. Suplementasi vitamin A diberikan untuk menurunkan tingkat KVA (Kekurangan Vitamin A) yang dapat menyebabkan xeropthalmia. Suplementasi Vitamin A diberikan oleh pemerintah untuk anak usia 611 bulan dengan kapsul warna biru dan anak usia 12-59 bulan dengan kapsu warna merah ${ }^{12}$.

Balita merupakan usia yang rawan mengalami masalah gizi, jika pada usia ini pertumbuhan dan perkembangan anak tidak terjadi secara optimal maka akan menjadi sumber daya manusia yang berkualitas ${ }^{13}$. Persentase permasalahan gizi di Jawa Timur tahun 2012 yaitu gizi buruk mencapai 1,15\% dan gizi kurang sebesar $5,71 \%{ }^{14}$. Berdasarkan uraian diatas maka rumusan masalah dalam penelitian ini adalah bagaimana hubungan perilaku Kadarzi dengan status gizi balita.

\section{METODE}

Penelitian ini merupakan jenis penelitian observasional dan ditinjau dari segi waktunya, penelitian ini merupakan cross sectional. Sampel dari penelitian ini adalah keluarga yang memiliki balita berusia 24-59 yang tinggal di Desa Salakkembang, Kecamatan Kalidawir, Kabupaten Tulungagung dengan responden ibu. Balita merupakan usia rawan mengalami masalah gizi karena usia ini merpakan masa pertumbuhan yang pesat ${ }^{15}$. Besar sampel minimal yang diperlukan dihitung menggunakan rumus besar sampel ${ }^{16}$ yang diperoleh hasil 72 sampel. Sampel diambil berdasarkan kesediaan responden dalam penelitian yang dilakukan di Desa Salakkembang wilayah kerja Puskesmas Tunggangri, Kecamatan Kalidawir, Kabupaten Tulungagung.

Variabel dependent yang digunakan pada penelitian adalah status gizi balita berdasarkan indeks $\mathrm{BB} / \mathrm{U}, \mathrm{TB} / \mathrm{U}$, dan $\mathrm{BB} / \mathrm{TB}$. Variabel independen pada penelitian ini yaitu Kadarzi yang terdiri dari lima indikator yaitu menimbang berat badan secara rutin, memberikan ASI eksklusif, makan beraneka ragam, menggunakan garam beryodium, dan pemberian suplemen zat gizi vitamin A pada balita. Karakteristik ibu yang diambil yaitu umur dan pendidikan, sedangkan karakteristik balita yang diambil yaitu usia, jenis kelamin dan berat bayi lahir. Pengambilan data didapatkan dari data primer dan data sekunder. Pengambilan data primer yaitu meliputi karakteristik ibu, karakteristik balita dan perilaku Kadarzi dengn menggunakan kuesioner sesuai dengan indikator. Berdasarkan indikator penimbangan berat badan dan suplementasi vitamin A dengan melihat (Kartu Menuju Sehat) KMS. Pengambilan data untuk indikator makan beraneka ragam menggunakan food recall dan penggunaan garam beryodium menggunakan tes yodium serta pemberian ASI eksklusif dengan melakukan wawancara. Data tentang status gizi didapatkan dari hasil penimbangan 
berat badan dan pengukuran tinggi badan. Data sekunder meliputi data penimbangan berat badan secara teratur selama 6 bulan berturut-turut dan pemberian vitamin $A$ selama 1 tahun terakhir yang tercatat di KMS.

Pada penelitian ini digunakan analisis univariat untuk melihat variabel karakteristik ibu dan karakteristik balita. Analisis data bivariat digunakan untuk mengetahui hubungan antara perilaku Kadarzi secara komposit dan berdasarkan masing-masing indikator dengan status gizi balita menggunakan Fisher Exact Test dengan signifikan diterima jika $p<0,05$.

Penelitian ini telah disetujui oleh komisi etik dari Fakultas Kesehatan Masyarakat Universitas Airlangga dengan nomor 309-KEPK dan dikeluarkan pada tanggal 6 Juni 2017 serta penelitian ini sudah memiliki ijin dari Bakesbangpol Provinsi Jawa Timur dengan nomor 070/7738/209.4/2017 dan Bakesbangpol Kabupaten Tulungagung dengan nomor 072/1362/601/2017.

\section{HASIL DAN PEMBAHASAN}

Karakteristik ibu pada penelitian ini menunjukkan umur ibu sebagian besar adalah antara 20-35 tahun (Tabel 1). Umur ibu dapat menunjukkan terjadinya risiko pada saat kehamilan. Ibu yang memiliki umur $\geq 35$ tahun berisiko 11 kali lebih besar untuk memiliki balita gizi buruk ${ }^{17}$. Pada variabel tingkat pendidikan ibu sebagian besar merupakan tamat SMA yaitu sebesar $51,4 \%$. Karakteristik balita menunjukkan sebagian besar balita berusia 48-60 bulan dan jenis kelamin balita sebagian besar laki-laki serta berat bayi lahir sebagian besar normal $(>2,5 \mathrm{~kg}$ ) (Tabel 1). Balita di Desa Salakkembang, Kecamatan Kalidawir sebagian besar memiliki status gizi baik (Tabel 1). Perilaku Kadarzi di Desa Salakkembang, Kecamatan Kalidawir memiliki beberapa indikator yang belum mencapai target sehingga perilaku Kadarzi belum mencapai target 80\% (Tabel 2)(Tabel 3).
Penimbangan secara rutin dilakukan untuk mengetahui pertumbuhan balita, jika terjadi hambatan dapat dilakukan pencegahan secara dini. Penimbangan secara rutin yang dilakukan balita dilihat dari KMS. Indikator Kadarzi pada penimbangan balita secara rutin dikelompokkan menjadi penimbangan secara tidak rutin ( $<4$ kali berturut-turut) dan rutin $(\geq 4$ kali berturut-turut) selama 6 bulan terakhir. Berdasarkan penelitian didapatkan proporsi balita yang rutin melakukan penimbangan yaitu $77,8 \%$. Angka tersebut belum mencapai target yang ditetapkan oleh Depkes ${ }^{1}$ dalam pedoman operasional keluarga sadar gizi di desa siaga sebesar $80 \%$. Terdapat beberapa faktor yang menyebabkan indikator penimbangan secara rutin tidak tercapai yaitu orang tua tidak membawa anaknya ke Posyandu dikarenakan pengetahuan ibu yang kurang, keterbatasan waktu, pekerjaan, informasi tentang Posyandu dan kualitas pelayanan kesehatan yang kurang serta tidak ada dukungan dari keluarga ${ }^{18}$.

Berdasarkan hasil uji statistik menunjukkan penimbangan berat badan secara rutin dengan status gizi balita tidak memiliki hubungan yang signifikan yaitu $B B / U$ $(p=0,198), T B / U(p=0,296)$, dan indeks $B B / T B$ $(p=0,693)$. Balita yang melakukan penimbangan secara rutin sebagian besar memiliki status gizi baik berdasarkan indeks $\mathrm{BB} / \mathrm{U}$ sebanyak $87,5 \%$. Balita yang menimbang secara rutin juga memiliki status gizi normal berdasarkan indeks TB/U sebanyak $73,2 \%$ dan BB/TB sebanyak $92,9 \%$. Penimbangan berat badan secara rutin yang dilakukan setiap bulan di Posyandu akan memperlihatkan status gizi balita, dimana anak yang sehat adalah anak yang mengalami kenaikan berat badan dikarenakan pertambahan tinggi badan ${ }^{19}$. Penelitian lain yang dilakukan oleh Pakhri dk ${ }^{20}$ juga menunjukkan tidak ada hubungan antara penimbangan secara rutin dengan status gizi balita. Tidak ada hubungan dikarenakan penimbangan berat badan digunakan untuk mengevaluasi status gizi, apakah terjadi obesitas ataupun gizi kurang ${ }^{21}$. 
Tabel 1. Distribusi Karakteristik Ibu, Balita dan Status Gizi Balita di Desa Salakkembang, Kecamatan Kalidawir, Tulungagung

\begin{tabular}{|c|c|c|}
\hline Variabel & $n$ & $\%$ \\
\hline \multicolumn{3}{|l|}{ Karakteristik Ibu } \\
\hline \multicolumn{3}{|l|}{ Umur Ibu } \\
\hline$<20$ Tahun & 1 & 1,4 \\
\hline 20-35 Tahun & 45 & 62,5 \\
\hline >35 Tahun & 26 & 36,1 \\
\hline \multicolumn{3}{|l|}{ Pendidikan Ibu } \\
\hline Tidak Tamat SD & 2 & 2,8 \\
\hline Tamat SD & 2 & 2,8 \\
\hline Tamat SMP & 25 & 34,7 \\
\hline Tamat SMA & 37 & 51,4 \\
\hline \multicolumn{3}{|l|}{ Karakteristik Balita } \\
\hline \multicolumn{3}{|l|}{ Usia Balita } \\
\hline 24-35 Bulan & 25 & 34,7 \\
\hline 36-47 Bulan & 18 & 25 \\
\hline 48-60 Bulan & 29 & 40,3 \\
\hline \multicolumn{3}{|l|}{ Jenis Kelamin } \\
\hline Laki-laki & 40 & 55,6 \\
\hline Perempuan & 32 & 44,4 \\
\hline \multicolumn{3}{|l|}{ BB Lahir } \\
\hline $\operatorname{BBLR}(<2,5 \mathrm{~kg})$ & 2 & 2,8 \\
\hline Normal $(\geq 2,5 \mathrm{~kg})$ & 70 & 97,2 \\
\hline \multicolumn{3}{|l|}{ Status Gizi Balita } \\
\hline \multicolumn{3}{|l|}{$\mathrm{BB} / \mathrm{U}$} \\
\hline Baik & 61 & 84,7 \\
\hline Kurang & 11 & 15,3 \\
\hline \multicolumn{3}{|l|}{$\mathrm{TB} / \mathrm{U}$} \\
\hline Normal & 51 & 70,8 \\
\hline Pendek & 21 & 29,2 \\
\hline \multicolumn{3}{|l|}{$\mathrm{BB} / \mathrm{TB}$} \\
\hline Normal & 67 & 93,0 \\
\hline Kurus & 5 & 7,0 \\
\hline
\end{tabular}

Tabel 2. Distribusi perilaku Kadarzi di Desa Salakkembang, Kecamatan Kalidawir

\begin{tabular}{|c|c|c|c|}
\hline & Perilaku Kadarzi & $\mathrm{n}$ & $\%$ \\
\hline \multirow{2}{*}{$\begin{array}{l}\text { Menimbang BB secara } \\
\text { rutin }\end{array}$} & Tidak Rutin (< 4 kali berturut-turut) & 16 & 22,2 \\
\hline & Rutin ( $\geq 4$ kali berturut-turut) & 56 & 77,8 \\
\hline \multirow[t]{2}{*}{ Memberikan ASI Eksklusif } & Tidak ASI Eksklusif & 16 & 22,2 \\
\hline & ASI Eksklusif & 56 & 77,8 \\
\hline \multirow[t]{2}{*}{ Makan Beranekaragam } & Tidak & 29 & 40,3 \\
\hline & Ya & 43 & 59,7 \\
\hline \multirow{2}{*}{$\begin{array}{l}\text { Menggunakan garam } \\
\text { beryodium }\end{array}$} & Tidak & 1 & 1,4 \\
\hline & Ya & 71 & 98,6 \\
\hline Pemberian Suplementasi & Tidak & 2 & 2,8 \\
\hline Zat Gizi Vitamin A & Ya & 70 & 97,2 \\
\hline \multirow[t]{2}{*}{ Kadarzi Secara Komposit } & Tidak & 30 & 41,7 \\
\hline & Ya & 42 & 58,3 \\
\hline
\end{tabular}


Tabel 3. Tabulasi Silang Perilaku kadarzi dengan Status Gizi Balita

\begin{tabular}{|c|c|c|c|c|c|c|c|c|c|c|c|c|}
\hline \multirow{3}{*}{ Perilaku Kadarzi } & \multicolumn{4}{|c|}{$\mathrm{BB} / \mathrm{U}$} & \multicolumn{4}{|c|}{$\mathrm{TB} / \mathrm{U}$} & \multicolumn{4}{|c|}{ BB/TB } \\
\hline & \multicolumn{2}{|c|}{ Baik } & \multicolumn{2}{|c|}{ Kurang } & \multicolumn{2}{|c|}{ Normal } & \multicolumn{2}{|c|}{ Pendek } & \multicolumn{2}{|c|}{ Normal } & \multicolumn{2}{|c|}{ Kurus } \\
\hline & $n$ & $\%$ & $\mathrm{n}$ & $\%$ & $\mathrm{n}$ & $\%$ & $\mathrm{n}$ & $\%$ & $\mathbf{n}$ & $\%$ & $\mathrm{n}$ & $\%$ \\
\hline \multicolumn{13}{|c|}{ Menimbang BB secara rutin } \\
\hline Tidak Rutin & 4 & 25 & 12 & 75 & 6 & 37,5 & 10 & 62,5 & 1 & 6,3 & 15 & 93,8 \\
\hline Rutin & 7 & 12,5 & 49 & 87,5 & 15 & 26,8 & 41 & 73,2 & 4 & 7,1 & 52 & 92,9 \\
\hline \multicolumn{13}{|l|}{ Memberikan ASI Eksklusif } \\
\hline Tidak & 4 & 25 & 12 & 75 & 7 & 43,8 & 9 & 56,3 & 1 & 6,3 & 15 & 93,8 \\
\hline Ya & 7 & 12,5 & 49 & 87,5 & 14 & 25 & 42 & 75 & 4 & 7,1 & 52 & 92,9 \\
\hline \multicolumn{13}{|l|}{ Makan Beranekaragam } \\
\hline Tidak & 8 & 27,6 & 21 & 72,4 & 16 & 55,2 & 13 & 44,8 & 2 & 6,9 & 27 & 93,1 \\
\hline Ya & 3 & 7,0 & 40 & 93 & 5 & 11,6 & 38 & 88,4 & 3 & 7 & 40 & 93 \\
\hline \multicolumn{13}{|l|}{$\begin{array}{l}\text { Menggunakan garam } \\
\text { beryodium }\end{array}$} \\
\hline Tidak & 0 & 0 & 1 & 100 & 0 & 0 & 1 & 100 & 0 & 0 & 1 & 100 \\
\hline Ya & 11 & 15,5 & 60 & 84,5 & 21 & 29,6 & 50 & 70,4 & 5 & 7 & 66 & 93 \\
\hline \multicolumn{13}{|c|}{ Pemberian Suplementasi Zat } \\
\hline \multicolumn{13}{|l|}{ Gizi Vitamin A } \\
\hline Tidak & 0 & 0 & 2 & 100 & 1 & 50 & 1 & 50 & 0 & 0 & 2 & 100 \\
\hline Ya & 11 & 15,7 & 59 & 84,3 & 20 & 28,6 & 50 & 71,4 & 5 & 7,1 & 65 & 92,9 \\
\hline \multicolumn{13}{|l|}{ Kadarzi Secara Komposit } \\
\hline Tidak & 10 & 32 & 21 & 67,7 & 17 & 54,8 & 14 & 45,2 & 3 & 9,7 & 28 & 90,3 \\
\hline $\mathrm{Ya}$ & 1 & 2,4 & 40 & 97,6 & 4 & 9,8 & 37 & 90,2 & 2 & 4,9 & 39 & 95,1 \\
\hline
\end{tabular}

Pemberian ASI eksklusif merupakan indikator Kadarzi yaitu anak diberikan makan hanya ASI saja mulai anak usia 0 sampai 6 bulan. Cakupan pemberian ASI eksklusif di Desa Salakkembang yaitu $77,8 \%$ dan angka tersebut belum mencapai target yang ditetapkan oleh sebesar $80 \%{ }^{1}$. Berdasarkan hasil uji statistik menunjukkan bahwa tidak ada hubungan yang signifikan antara pemberian ASI eksklusif dengan status gizi balita berdasarkan indeks $B B / U \quad(p=0,198), T B / U$ $(p=0,127)$, dan $B B / T B \quad(p=0,693)$. Ibu yang memberikan anaknya ASI eksklusif sebagian besar memilki balita status gizi baik berdasarkan indeks $\mathrm{BB} / \mathrm{U} 87,5 \%$. Balita yang mendapatkan ASI eksklusif juga memiliki status gizi normal berdasarkan indeks TB/U sebanyak $75 \%$, dan BB/TB sebanyak 92,9\% .Balita yang mendapatkan ASI eksklusif dan tidak ASI eksklusif memilki peluang yang sama untuk memiliki status gizi baik ataupun status gizi kurang $^{22}$. Tidak ada hubungan dikarenakan ASI eksklusif tidak hanya berperan untuk pertumbuhan balita tetapi juga sebagai daya tahan tubuh. ASI memiliki komponen bioaktif seperti sekresi Ig A yang memiliki fungsi dalam daya tahan tubuh untuk melawan penyakit infeksi ${ }^{23}$. Hasil penelitian ini sejalan dengan penelitian Ridzal $\mathrm{dkk}^{\mathrm{e}}$ yaitu balita yang menerima ASI eksklusif dan tidak ASI eksklusif memiliki peluang yang sama untuk status gizi baik maupun status gizi kurang .

Terdapat faktor penyebab tidak diberikannya ASI eksklusif dikarenakan produksi ASI yang kurang atau ASI tidak keluar. Produksi ASI dapat dipengaruhi dari asupan zat gizi ibu serta keadaan psikologis ibu seperti merasa cemas setelah melahirkan ${ }^{24}$. Dukungan keluarga juga memiliki kontribusi yang baik agar ibu memberikan ASI eksklusif baik berupa dukungan informasional, dukungan instrumental, dukungan penilaian maupun emosional $\left.\right|^{25}$.

Indikator Kadarzi yaitu makan beraneka ragam dikelompokkan menjadi tidak makan beraneka ragam dan makan beranekaragam. Makan beraneka ragam ditunjukkan berdasarkan hasil food recall selama 2 hari dalam satu minggu terakhir. Balita dikatakan makan beraneka ragam jika selama 2 hari tersebut mengonsumsi karbohidrat, protein hewani, sayur dan buah ${ }^{1}$. 
Balita yang makan beraneka ragam belum mencapai target $80 \%$ yang ditetapkan Depkes ${ }^{1}$ yaitu balita yang makan beraneka ragam mencapai 59,7\%. Berdasarkan hasil food recall penyebab balita tidak makan beragam adalah karena tidak mengonsumsi sayur dan buah. Pengetahuan ibu tentang manfaat makanan pokok lebih tinggi dibandingkan dengan manfaat lauk hewani dan nabati serta sayur dan buah, hal ini yang dapat menyebabkan balita tidak makan beraneka ragam ${ }^{26}$.

Hasil uji statistik menunjukkan terdapat hubungan yang signifikan antara makan beraneka ragam dengan status gizi balita BB/U $(p=0,021)$ dan TB/U $(p-0,000)$ namun tidak pada $B B / T B(p=0,683)$. Balita memiliki status gizi normal pada indeks $B B / T B$ sebanyak 93\%. Hasil ini sejalan dengan penelitian Nadimin ${ }^{27}$ yaitu makan beraneka ragam berhubungan dengan status gizi balita $\mathrm{BB} / \mathrm{U}$.

Mengkonsumsi makanan beraneka ragam diharapkan dapat memperbaiki status gizi, terutama balita yang mengalami masa pertumbuhan dan perkembangan karena tidak ada jenis makanan yang memilik semua kandungan zat gizi. Mengkonsumsi makan beraneka ragam memperlihatkan adanya kesadaran keluarga tentang pemenuhan gizi untuk menjaga kesehatan ${ }^{1}$. Makan beraneka ragam tidak hanya berdasarkan jenis bahan makanan tetapi jumlah makanan sehingga dapat mencukupi kebutuhan tubuh. Penelitian yang dilakukan di Ghana menunjukkan bahwa anak yang makan beraneka ragam dengan jumlah yang sesuai meningkatkan kesehatan dan menurunkan masalah gizi dibandingkan anak yang tidak mengkonsumsi makanan beraneka ragam ${ }^{9}$.

Sebagian besar rumah tangga di Desa Salakkembang sudah menggunakan garam beryodium. Garam beryodium diketahui dari tes yodina yaitu jika garam mengandung yodium maka akan berubah warna menjadi ungu. Berdasarkan penelitian didapatkan proporsi keluarga yang menggunakan garam beryodium yaitu $98,6 \%$ dan angka tersebut sudah sesuai dengan target yang ditetapkan oleh Depkes RI sebesar $90 \%{ }^{1}$. Berdasarkan uji statistik menunjukkan tidak ada hubungan antar penggunaan garam beryodium dengan status gizi balita $B B / U \quad(p=0,847), \quad T B / U$ $(p=0,708)$ dan BB/TB $(p=0,931)$. Penelitian ini berbeda dengan penelitian Karolina ${ }^{28}$ yaitu yang menemukan adanya hubungan antara penggunan garam beryodium dengan status gizi balita. Balita yang menggunakan garam beryodium $84,5 \%$ memiliki status gizi baik berdasarkan indeks $\mathrm{BB} / \mathrm{U}$ serta statu gizi normal berdasarkan indeks $T B / U$ sebanyak 70,4\%, dan BB/TB sebanyak $93 \%$.

Penggunaan garam beryodium juga disertai cara penyimpanan yang tepat agar konsentrasi yodium pada garam tetap terjaga. Garam beryodium tidak tahan terhadap suhu panas serta penggunaan wadah yang terbuka akan menyebabkan garam mudah menguap yang menyebabkan konsentrasi yodium pada garam menjadi semakin kecil ${ }^{29}$. Penyimpanan garam beryodium sebaiknya dalam wadah tertutup dan penggunaan garam beryoudium pada saat memasak ketika makanan telah matang dan suhu makanan tidak terlalu panas.

Indikator Kadarzi yang terakhir yaitu suplementasi vitamin A pada balita. Vitamin A berperan penting untuk pertumbuhan balita dan kekurangan vitamin A dapat menyebabkan xeropthalmia. Pemberian suplemen vitamin A dilakukan 2 kali selama 1 tahun terakhir yaitu pada bulan Februari dan Agustus. Berdasarkan penelitian balita yang mendapatkan suplemen vitamin A sebesar $97,2 \%$ dan angka tersebut sudah mencapai target $80 \%$. Pemberian suplemen zat gizi vitamin A tidak memiliki hubungan yang signifikan dengan status gizi berdasarkan indeks $B B / U(p=0,716), T B / U$ $(p=0,501)$, dan $B B / T B(p=0,865)$. Hasil ini sama dengan penelitian yang dilakukan oleh Nadimin ${ }^{27}$ yaitu suplementasi zat gizi vitamin A dengan status gizi balita tidak memiliki hubungan yang signifikan. Balita yang mendapatkan suplementasi vitamin A 84,3\% memiliki status gizi baik berdasarkan indeks $\mathrm{BB} / \mathrm{U}$. Balita juga memiliki status gizi normal pada $\mathrm{TB} / \mathrm{U}$ sebesar $71,4 \%$ dan $\mathrm{BB} / \mathrm{TB}$ sebesar $92,9 \%$.

Balita diketahui mendapatkan suplementasi vitamin A berdasarkan KMS karena balita yang melakukan penimbangan rutin terutama pada bulan Februari dan Agustus juga mendapatkan suplemen vitamin A. Balita yang tidak mendapatkan 
suplementasi vitamin A adalah balita yang tidak rutin ke Posyandu untuk melakukan penimbangan. Vitamin A juga berfungsi untuk mengurangi prevalensi infeksi pernafasan berat, gastroenteritis akut dan septikemia ${ }^{30}$.

Perilaku Kadarzi secara komposit yaitu keluarga dikatakan memiliki perilaku Kadarzi jika memenuhi 5 indikator. Keluarga yang berperilaku Kadarzi baik memilki proporsi sebesar $58,3 \%$, nilai ini belum mencapai target nasional yaitu $80 \%$. Perilaku Kadarzi belum tercapai karena terdapat beberapa indikator yang belum mencapai target yaitu menimbang berat badan secara rutin, pemberian ASI ekslusif dan makan beraneka ragam. Berdasarkan uji statistik antara perilaku Kadarzi secara komposit dengan status gizi balita menunjukkan bahwa terdapat hubungan yang signifikan berdasarkan indeks $\mathrm{BB} / \mathrm{U}$ $(p=0,010)$, dan $T B / U(p=0,000)$, namun tidak memiliki hubungan dengan indeks $\mathrm{BB} / \mathrm{TB}$ $(p=0,368)$. Penelitian yang dilakukan di wilayah kerja Puskesmas Gajah 1 Demak juga menunjukkan hubungan yang signifikan antara status gizi balita $(B B / U)$ dengan perilaku Kadarzi ${ }^{31}$. Semakin baik keluarga berperilaku Kadarzi maka status gizi $\mathrm{BB} / \mathrm{U}$ dan TB/U semakin baik. Rumah tangga dengan perilaku Kadarzi yang kurang baik berpeluang meningkatkan risiko stunting pada anak balita 1,21 kali lebih besar daripada keluarga yang berperilaku Kadarzi baik ${ }^{32}$.

Perilaku Kadarzi dengan status gizi balita memiliki keterkaitan, pada penilaian status gizi berdasarkan indek BB/U dapat memperlihatkan perubahan yang mendadak seperti infeksi atau perubahan pola konsumsi ${ }^{21}$. Kadarzi dengan status gizi berdasarkan indeks TB/U menggambarkan masalah gizi masa lampau ${ }^{21}$. Kadarzi dengan status gizi berdasarkan indeks BB/TB dapat digunakan untuk mengetahui keadaan yang telah lalu dan sekarang dengan faktor umur dikesampingkan ${ }^{21}$.

\section{KESIMPULAN}

Semakin baik penerapan perilaku Kadarzi pada keluarga yang memenuhi lima indikator maka semakin baik status gizi balita berdasarkan indeks BB/U dan TB/U. Makan beraneka ragam merupakan indikator yang penting dalam Kadarzi yang memilki kaitan penting dengan status gizi balita berdasarkan indeks BB/U dan TB/U. Capaian Kadarzi yang belum terpenuhi yaitu penimbangan berat badan secara rutin, pemberian ASI eksklusif dan makan beranekaragam. Diharapkan ibu menyediakan makanan bervariasi yaitu sumber karbohidrat, lauk hewani, sayur setiap hari agar konsumsi menjadi beragam. Pihak Puskesmas dapat memberikan pemahaman tentang perilaku Kadarzi sehingga masyarakat dapat menerapkan dan capaian Kadarzi dapat tercapai sesuai target.

\section{ACKNOWLEGMENT}

Terimakasih kepada seluruh pengajar Prodi S1 IImu Gizi Fakultas Kesehatan Masyarakat Universitas Airlangga yang selalu sabar membimbing dan mendukung peneliti sehingga dapat menyelesaikan artikel ini. Ucapan terimakasih juga saya berikan kepada seluruh responden yang bersedia ikut serta dalam penelitian di Desa Salakkembang, Kecamatan Kalidawir Kabupaten Tulungagung dan teman-teman yang telah membantu dalam penelitian.

\section{REFERENSI}

1. Departemen Kesehatan RI. Keputusan Menteri Kesehatan Republik Indonesia Nomor 747 Tentang Pedoman Operasional Keluarga Sadar Gizi di Desa Siaga. 2007.

2. Dinas Kesehatan Jatim. Pembahasan Hasil Survei Kadarzi. 2010.

3. Dinas Kesehatan Kabupaten Tulungagung. Profil Kesehatan Tahun 2015. 2016.

4. Hariyadi, Ekayanti I. Analisis Pengaruh Perilaku Keluarga Sadar Gizi terhadap Stunting di Provinsi Kalimantan Barat. Jurnal Teknologi dan Kejuruan 2011; 34(1): 71-80.

5. Hidayat TS, Jahari AB. Perilaku Pemanfaatan Posyandu Hubungannya dengan Status Gizi Balita dan Morbiditas Balita. Buletin Penelitian Kesehatan 2012; 40(1): 1-10. 
6. Pramono D, Utami NW, Maemun N. Hubungan Pengetahuan dengan Motivasi Ibu Memekrisakan Balita ke Posyandu Wilayah Kerja Puskesmas Pagak Kabupaten Malang. Nursing News 2016; 1(1): 22-60.

7. Al-Ruzaihan SA, Al-Ghanim AA, Bu-Haimed $\mathrm{BM}$, Al-Rajeh HK, Al-Subaiee WR, AlRowished FH, Badger-Emeka LI. Effect of Maternal Occupation on Breast Feeding Among Females in Al-Hassa, Southeastern Region of KSA. Journal of Taibah University Medical Science 2017; 12(3): 235-240.

8. Giri M, Muliarta IW, Wahyuni NP. Hubungan Pemberian ASI Eksklusif dengan Status Gizi Balita Usia 6-24 Bulan di Kampung Kajanan Buleleng. Jurnal Sains dan Teknologi 2013; 2(1): 184-192.

9. Frempong RBF, Annim SK. Dietery Diversity and Child Malnutrition in Ghana. Available from https://ac.elscdn.com/S240584401631180X/1-s2.0-

S240584401631180X-

main.pdf?_tid=b364ce56-b20e-11e7-98bc00000aab0f6b\&acdnat $=1508116366 \_c 0 e 5$ d4d599f04700d054b1ff650efae6. Diakses 14 Oktober 2017.

10. Fekadu Y, Mesfin A, Haile D, Stoecker BJ. Factors Associated with Nutritional Status of Infants Young Children in Somali Region, Ethiopia: A Cross-Sectional Study. Available from

https://www.ncbi.nlm.nih.gov/pmc/article s/PMC4557759/. Diakses pada 14 Oktober 2017.

11. DeviM. Hubungan Penggunaan Garam Beryodium dengan Pertumbuhan Linier Anak. Jurnal Teknologi Industri Boga dan Busana. Jurnal Teknologi Industri Boga dan Busana 2012; 3(1): 52-57.

12. Departemen Kesehatan RI. Pedoman Manajemen Suplemen Vitamin A. 2009.

13. Departemen Kesehatan RI. Pedoman Strategi KIE Keluarga Sadar Giizi. 2007.

14. Departemen Kesehatan RI. Profil Kesehatan Provinsi Jawa Timur Tahun 2012. 2013.

15. Kartika V, Adriani M. Pola Asuh Makan Balita dengan Status Gizi Kurang di Jawa Timur, Jawa Tengah dan Kalimantan Tengah, Tahun 2011. Buletin Penelitian Sistem Kesehatan 2013; 16(2): 185-193.
16. Lameshow, Luwangga SK. Besar Sampel dalam Peneitian Kesehatan. Yogyakarta; Gajah Mada University Press; 1997.

17. Khotimah H, Kuswandi K. Hubungan Karakteristik Ibu dengan Status Gizi Balita di Desa Sumur Bandung Kecamatan Cikulur Kabupaten Lebak Tahun 2013. Jurnal Obstretika Scientia 2014; 2(1): 146-162.

18. Sihotang HMI, Rahma N. Faktor Penyebab Penurunan Kunjungan Bayi di Posyandu Puskesmas Langsat Pekanbaru Tahun 2016. Journal Endurance 2017; 2(2): 168177.

19. Welasasih BD, Wirjatmadi RB. Beberapa Faktor yang Berhubungan dengan Status Gizi Balita Stunting. The Indonesian Journal of Public Health 2012; 8(2): 99-104.

20. Pakhri A, Sirajuddin, Aini N. Profil Keluarga Sadar Gizi dan Hubungannya dengan Status Gizi di Kecamatan Bontamarannu. Media Gizi Pangan 2010; 10(2): 33-38.

21. Adriani M, Wirjatmadi B. Peranan Gizi dalam Siklus Kehidupan. Jakarta; 2012: 152-232.

22. Ridzal M, V Hadju, S Rochimiwati. . Hubungan Pola Pemberian ASI dengan Status Gizi Anak Usia 6-23 Bulan di Wilayah Pesisir Kecamatan Tallo Kota Makassar. Jurnal MKMI 2013; 1: 1-12.

23. Breakey AA, Hinder $K$, Valeggia $C R$, Sinofsky A, Ellison PT. Illness in Breastfeeding Infants Relates to Concentration of Lactoferin and Scretory Immunologlobulin A in Mother's Milk. Evol Med Public Health 2015; (1): 21-31.

24. Saraung MW, Rompas S, Bataha YB. Analisis Faktor-faktor yang Berhubungan dengan Produksi ASI pada Ibu Post Partum di Puskesmas Ronotana Weru. E-Journal Keperawatan 2017; 5(2):1-8.

25. Oktalina O, Muniroh L, Adiningsih S. Hubungan Dukungan Suami dan Keluarga dengan Pemberian ASI Eksklusif pada Ibu Anggota Kelompok Pendukung ASI (KPASI). Media Gizi Indonesia 2015; 10(1): 6470.

26. Aditianti, Prihatini S, Hermina. Pengetahuan, Sikap dan Perilaku Indiviu tentang Makanan Beraneka Ragam sebagai Salah Satu Indikator Keluarga Sadar Gizi 
(Kadarzi). Buletin Penelitian Kesehatan 2016; 44(2): 117-126.

27. Nadimin Hubungan Keluarga Sadar Gizi dengan Status Gizi Balita di Kabupaten Takalar Sulawesi Selatan. Jurnal Madia Gizi Pangan 2010; 10(2): 1-7.

28. Karolina E, Nasution E, Aritonang EY. Hubungan Perilaku Kadarzi dengan Status Gizi Balita Usia 12-59 Bulan di Wilayah Kerja Puskesmas Blangkejeren Kecamatan Blangkejeren Kabupaten Gayo Lues Tahun 2012. Gizi, Kesehatan Reproduksi dan Epidemiologi 2013; 2(2): 1-11.

29. Sugiani $H$, Previyanti $P$, Sukrido, Pratomo U. Penentuan Pengaruh Pemanasan dan Waktu Penyimpanan Garam Beriodium Terhadap Kalium lodat. Jurnal Chimica et Natura Acta 2015; 3(2): 66-69.
30. Ahmad SM, Raqib R, Qadri F, Stephensen C. The Effect of Newborn Vitamin A Suplementation on Infant Immune Function: Trial Design, Interventions and Baseline Data. Contenporary Clinical Trials 2014; 39(2): 269-279.

31. Aisyaroh N, Zulfa SA, Zulaikhah ST. Hubungan Perilaku Kadarzi (Keluarga Sadar Gizi) dengan Status Gizi Balita di Wilayah Kerja Puskesmas Gajah 1 Demak. Jurnal Ilmu Kesehatan 2014; 9(19)

32. Hariyadi, Ekayanti I. Analisi Pengaruh Perilaku Keluarga Sadar Gizi terhadap Stunting di Provinsi Kalimantan Barat. Jurnal Teknologi dan Kejuruan 2011; 34(1): 71-80 